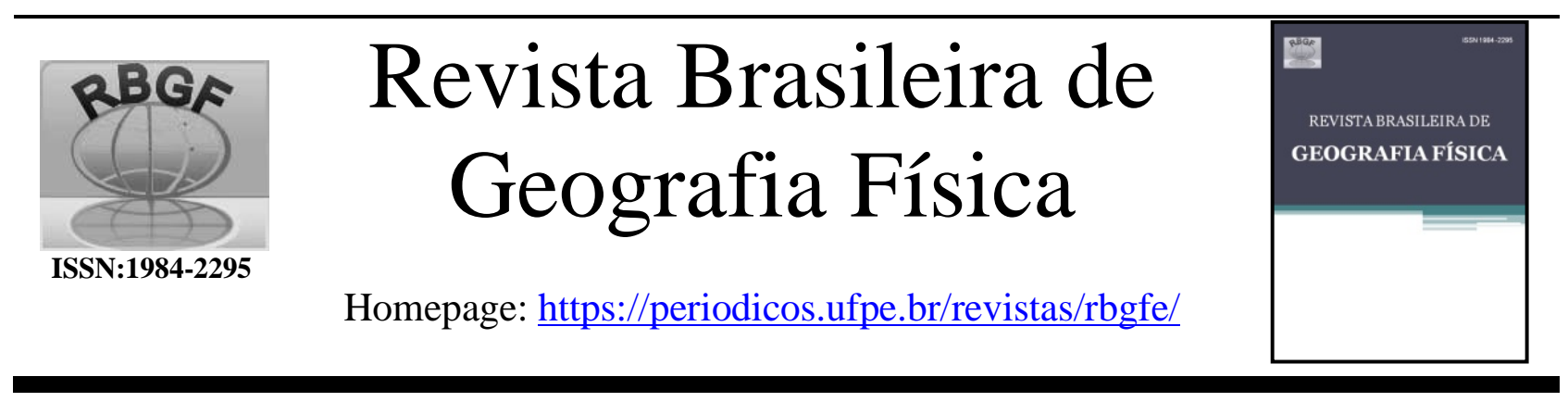

\title{
Dinâmica de Queimadas no Município de Cuiabá-MT por Sensoriamento Remoto
}

Noelto da Cruz Teixeira ${ }^{1}$, Victor Hugo de Morais Danelichen², Osvaldo Alves Pereira ${ }^{3}$, Guilherme Barros Seixas ${ }^{4}$

'Mestrando em Ciências ambientais, Universidade de Cuiabá, Campus Barão, 222. CEP 78005-300, Cuiabá, Mato Grosso. (65) 2136 0636. noelto.teixeira@cba.ifmt.edu.br.² Professor doutor e Pesquisador, Mestrado em Ciências Ambientais, Universidade de Cuiabá, Campus Barão, 222, CEP 78005-300, Cuiabá, Mato Grosso. (65) 3363-1729.ufmt danelichen@ fisica.br. ${ }^{3}$ Professor doutor e Pesquisador, Mestrado em Ciências Ambientais, Universidade de Cuiabá, Campus Barão, 222, CEP 78005-300, Cuiabá, Mato Grosso. (65) 3363-1729.osvaldoalvesfu@ gmail.com. ${ }^{4}$ Professor doutor e Pesquisador, Instituto Federal de Mato Grosso, IFMT campus Cuiabá, 95, CEP 78005-200, Cuiabá, Mato Grosso. guilherme.seixas@ cba.ifmt.edu.br. Artigo recebido em 28/07/2020 e aceito em 20/04/2021

\section{R E S U M O}

O bioma Cerrado brasileiro possui diversas fitofisionomias e um elevado índice de ocupação humana com destaque na produção agropecuária. Apesar de seu potencial biológico enfrenta ameaças constantes de queimadas devido à conversão da vegetação em parcelas destinadas a agricultura e pastagem. Neste contexto o objetivo deste trabalho foi identificar e relacionar a dinâmica espacial e temporal das queimadas no município de Cuiabá-MT, com as variáveis microclimáticas, classes de vegetação e declividades do terreno por meio do uso de recursos de sensoriamento remoto. Foram utilizados os índices espectrais NBR (Normalized Burn Ratio), NBR2 (Variation of Normalized Burn Ratio) e NDVI (Normalized Difference Vegetation Index) extraídos das imagens Landsat 8 e focos de calor fornecido pelo banco de dados de queimadas do INPE (Instituto Nacional de Pesquisas Espaciais) no período de 2013 a 2017. Os índices espectrais foram extraídos de 25 imagens referente a órbita 226 e ponto 071, utilizando o programa Erdas Imagine, e os mapas de fogo do estimador de Kernel presente no ArcGis 10.3 a fim de avaliar a distribuição e o padrão das queimadas na área proposta. Houve $50,68 \%$ de coincidência do total dos focos de calor sobre as áreas queimadas de referência com maior percentual de $72,12 \%$ em 2017 e menor em 2014 de 12,95\%. Estes resultados permitiram elaborar mapas com padrão de queimada característico e evidenciar as classes mais atingidas pelo fogo em todo o período estudado.

Palavras-chave: Landsat 8, incêndio, padrão espacial.

\section{Dynamics of Fires in the Municipality of Cuiabá-MT by Remote Sensing}

\begin{abstract}
A B S T R A C T
The Brazilian Cerrado biome has several phytophysiognomies and a high rate of human occupation, with emphasis on agricultural production. Despite its biological potential, it faces constant threats of burning due to the conversion of vegetation into plots for agriculture and pasture. In this context, the objective of this work was to identify and relate the spatial and temporal dynamics of the fires in the municipality of Cuiabá-MT, with the microclimate variables, classes of vegetation and slopes of the land through the use of remote sensing resources. The spectral indexes NBR (Normalized Burn Ratio, NBR2 (Variation of Normalized Burn Ratio) and NDVI (Normalized Difference Vegetation Index) extracted from Landsat 8 images and heat sources provided by the INPE (Instituto Nacional de Space Research) from 2013 to 2017. The spectral indexes were extracted from 25 images referring to orbit 226 and point 071, using the Erdas Imagine program, and the fire maps of the Kernel estimator present in ArcGis 10.3 in order to evaluate the distribution and the pattern of fires in the proposed area. There was a $50.68 \%$ coincidence of the total number of hot spots on the reference burned areas, with a higher percentage of $72.12 \%$ in 2017 and lower in 2014 of $12.95 \%$. These results made it possible to elaborate maps with a characteristic burning pattern and to highlight the classes most affected by fire throughout the studied period. Keywords: OLI, fire, spatial pattern.
\end{abstract}

\section{Introdução}

Segundo Souza (2017) a utilização do fogo sempre esteve presente por milhares de anos e seus efeitos são notórios para todos os que convivem com o bioma Cerrado. A herança das características fisionômicas (cortiça espessa) e os benefícios advindos da rebrota em curto período de 
tempo após a queima (como alimentos para ruminantes, quebra da dormência vegetativa para a germinação das sementes) dentre outros, revelam as diferenças em relação aos outros biomas existentes (Lombardi, 2005).

De acordo com Daldegan et al. (2019), a remoção da vegetação natural no Brasil está relacionada as queimadas. Outro fator é a limpeza das áreas para o cultivo agrícola, bem como a queima do lixo doméstico em áreas urbanas no qual possui facilidade de combustão (Lopes et al. 2018).

Apesar da vegetação do Cerrado ser dependente das queimadas, White e White (2015) apontam que sua elevada frequência, também, é responsável por danos ambientais. Elas causam impactos ambientais decorrente das emissões e incorporações dos principais gases nocivos na atmosfera como o dióxido de carbono $\left(\mathrm{CO}_{2}\right)$, monóxido de carbono $(\mathrm{CO})$, óxidos nitrosos $\left(\mathrm{NO}_{3}\right)$, hidrocarbonetos e partículas de aerossóis (Pereira et al., 2016). Ainda, são responsáveis pela poluição do ar, mudanças climáticas em diferentes escalas e prejuízos relevantes à saúde humana, principalmente em aglomerados urbanos (doenças respiratórias e intoxicações adquiridas), além de comprometer a sustentabilidade do ecossistema com a redução ou extinção de muitas espécies vegetais e animais.

Para Seger (2015) nos eventos de queimadas o que caracteriza a propagação do fogo é o material combustível florestal vivo ou morto de composição lenhosa ou foliar sobre a superfície do solo. A quantidade deste material, as condições atmosféricas locais e a precipitação pluviométrica são fatores determinantes para a ocorrência e a propagação do fogo na queima da vegetação devido o teor de umidade presente no material combustível, assim como a quantidade de energia necessária para o início do processo de ignição (Oliveira, White e Ribeiro, 2018), ou seja, quanto maior a umidade, maior a dificuldade do mesmo entrar em combustão (White 2018).

Um outro fator relevante à queima é a topografia. Ela determina a posição de diversos tipos de materiais combustíveis, afeta o seu crescimento e a sua inflamabilidade decorrente dos seus efeitos causados pelo clima e caracteriza os ventos convectivos, revelando três fatores topográficos importantes tais como a exposição das encostas, a declividade e a altitude. Um dos efeitos importante da configuração do relevo sobre o microclima de cada localidade é a variação da umidade do solo e da vegetação decorrente da forma e da posição com que as encostas se apresentam em relação a radiação solar, (ICMBIo, 2016).

O Estado de Mato Grosso em geral, possui um período de seca intensa, entre os meses de julho a setembro. Nesta ocasião a região de Cuiabá-MT experimenta um período de estiagem, propício para a deflagração de focos de calor e a vegetação, torna-se um meio favorável para a propagação do fogo com diferentes intensidades e danos ambientais conforme as características do ambiente e dos combustíveis distribuídos na superfície do solo.

Segundo Silva, Costa e Matricardi (2017), a detecção e o monitoramento de focos de calor, atualmente, é feito com dados obtidos por sensores orbitais que operam na faixa do infravermelho termal, aproximadamente 10,4 a 12,5 $\mu \mathrm{m}$. Estes focos de calor ativos pode resultar em queimadas na vegetação em todo o Brasil e são obtidos por diversos satélites de baixa resolução espacial e alta resolução temporal, ficando disponível, gratuitamente a todos usuários, pelo Instituto Nacional de Pesquisas Espaciais (INPE, 2019).

Conforme Rodrigues et al. (2018), uma tecnologia essencial na avaliação de superfícies queimadas com resoluções espacial e temporal apropriadas para a identificação destes fenômenos nas últimas décadas é o uso do sensoriamento remoto.

No processo de monitoramento de queimadas as informações extraídas de imagens de sensoriamento remoto em ambientes de Sistema de Informações Geográficas (SIG) tem relevante destaque na medida em que é possível estabelecer relações entre as variáveis biofísicas e antrópicas (Lopes et al., 2018). As variáveis biofísicas segundo Pereira et al. (2016), apresentam sensibilidades às mudanças das características espectrais nos diferentes tipos de vegetação por serem provenientes de simples expressões matemáticas, envolvendo valores de reflectâncias.

Diante do exposto, o conhecimento da distribuição espacial do fogo e sua dimensão permite a confecção de mapas temáticos para mostrar locais com maior ou menor ocorrência deste fenômeno na paisagem, com o propósito de compreender o comportamento das queimadas e gerir ações inerentes à prevenção, combate e minimização dos possíveis danos causados ao ambiente e a população (Silva, Pestana e Martins, 2019).

O estimador de densidade de kernel é uma ferramenta existente nos SIGs de fundamental importância para subsidiar a análise da distribuição espacial de variáveis ambientais, através de técnica 
de interpolação exploratória de eventos pontuais que ocorrem em uma determinada área $\mathrm{e}$ disponibiliza mapas de densidades de forma rápida e eficiente, incluindo as queimadas (Fiorelli et al., 2019).

Diversos pesquisadores, analisaram ocorrências e distribuição espaço-temporal de queimadas no Brasil, utilizando o estimador de Kernel: Jesus et al. (2020), verificaram que os biomas Amazônia e Cerrado possuem, respectivamente, os maiores focos de calor, com maior área queimada para o bioma Cerrado. Fiorelli et al. (2019) observaram as maiores ocorrências de queimadas na cidade de Jaú-SP, durante a estação mais seca do ano, além de outros autores como Botelho et al. (2020), Ribeiro et al. (2020) e Sales et al. (2019).

Neste sentido, identificar possíveis padrões de queimadas em locais de maiores ocorrências em um determinado período, torna-se importante para entender a dinâmica do fogo do ponto de vista ambiental e social pois, viabiliza tomadas de decisões por meio de políticas públicas direcionadas às ações de planejamento do uso da terra e mitigação dos impactos causados no ambiente.
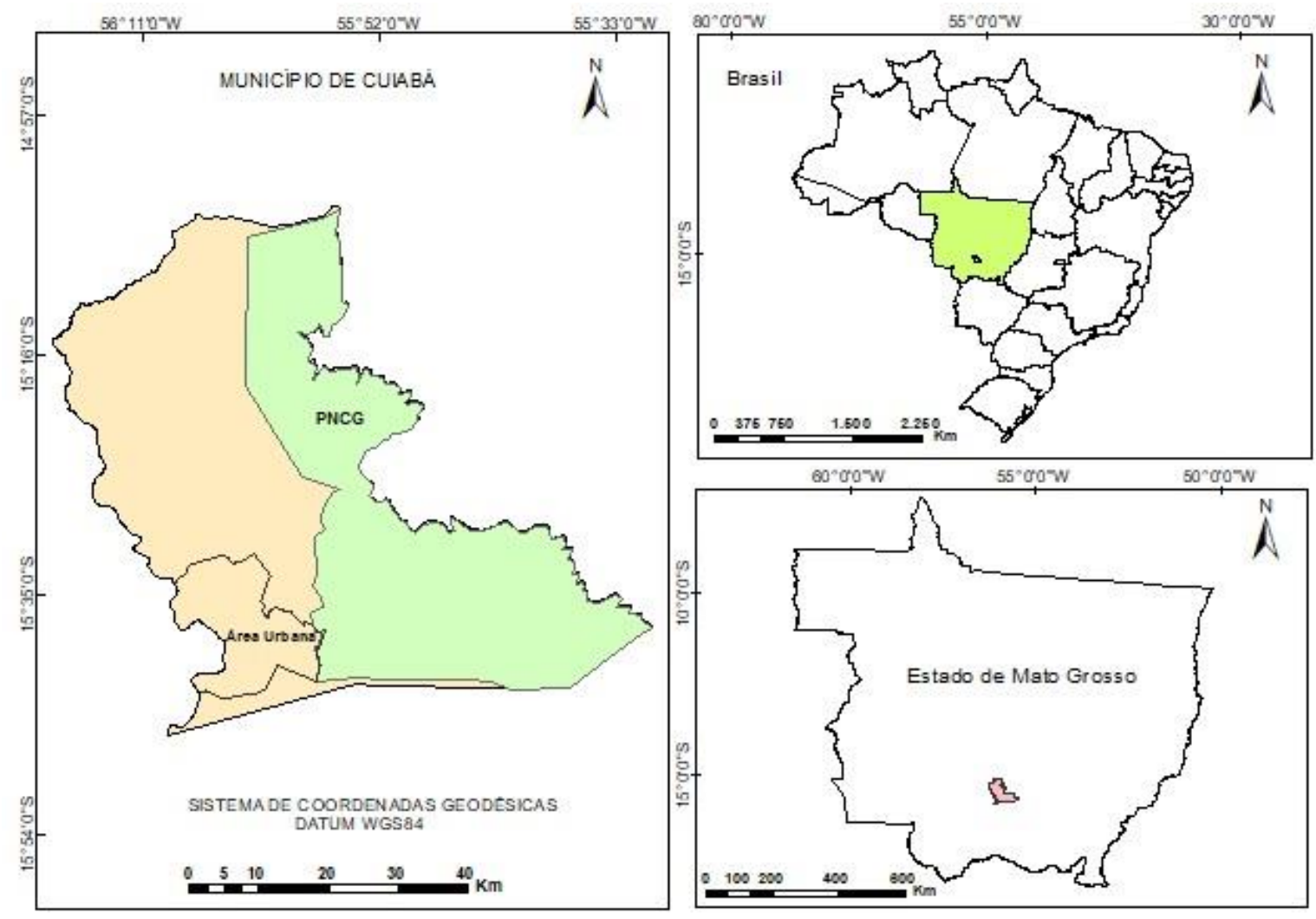

Com o intuito de compreender os padrões de queimadas no município de Cuiabá o objetivo

Figura 1. Localização geográfica do município de Cuiabá. Fonte: Adaptado pelos Autores. 
É importante ressaltar a presença da área do Parque nacional de Chapada dos Guimarães (PNCG) no município, que corresponde a quase metade da superfície total da área de estudo, incluindo sua zona de amortecimento de proteção integral.

O município de Cuiabá, está inserido no bioma savânico do Cerrado brasileiro (Ferreira; Ugeda Júnior, 2020). Sua vegetação natural é composta de cerrado, cerradão, mata ciliar, mata semidecídua e mata de encosta, com a grande parte dessa vegetação suprimida desde os anos 70 do século passado em decorrência do aumento de áreas agricultáveis e a expansão urbana (Junior et al., 2020).

Conforme o mesmo autor, o clima da região é semiúmido e classificado como Aw segundo a classificação de Köppen com período seco nos meses de maio a setembro, apresentando precipitação média de $1372 \mathrm{~mm}$ por ano e temperatura do ar média anual de $26,9{ }^{\circ} \mathrm{C}$.

\section{Dados de entrada}

Neste trabalho foram utilizados os dados de reflectância como produtos extraídos das imagens do sensor Operational Land Imager (OLI) com resolução espacial de $30 \mathrm{~m}$ a bordo do satélite Landsat 8 referente a órbita 226, ponto 07 e adquirida gratuitamente junto ao Centro de Ciências Platform Architecture Processing (ESPA) (http://espa.cr.usgs.gov/) do United States Geological Survey (USGS, 2019) no intervalo de 2013 a 2017 como mostra a Tabela 1.

Tabela 1: Dados das imagens do sensor OLI.

\begin{tabular}{lccc}
\hline ANO & \multicolumn{2}{c}{ DATA } & BANDAS \\
\hline $\mathbf{2 0 1 3}$ & $29 / 05$ & $15 / 07$ & $4,5,6$ e 7 \\
& $01 / 08$ & $17 / 08$ & \\
$\mathbf{2 0 1 4}$ & $16 / 05$ & $03 / 07$ & $4,5,6$ e 7 \\
& $04 / 08$ & $05 / 09$ & \\
$\mathbf{2 0 1 5}$ & $16 / 05$ & $03 / 07$ & $4,5,6$ e 7 \\
& $04 / 08$ & $05 / 09$ & \\
$\mathbf{2 0 1 6}$ & $05 / 05$ & $08 / 07$ & $4,5,6$ e 7 \\
& $24 / 07$ & $25 / 08$ & \\
& $10 / 09$ & $26 / 09$ & \\
$\mathbf{2 0 1 7}$ & $08 / 05$ & $24 / 08$ & $4,5,6$ e 7 \\
& $11 / 07$ & $27 / 07$ & \\
& $12 / 08$ & $28 / 08$ & \\
& $13 / 09$ & & \\
\hline
\end{tabular}

Fonte: Adaptado de INPE (2019).
Conforme a Tabela 1 o número de cena obtidas para cada ano oscilaram entre 4 e 7 em consequência da presença de nuvens, as quais foram devidamente eliminadas afim de evitar problemas inerente à extração das informações contidas nas imagens.

As imagens adquiridas já se encontram corrigidas das inconsistências atmosféricas pois, a USGS, nos últimos anos, está disponibilizando imagens com correção atmosférica de maior nível de qualidade, apresentado uma melhoria do produto de refletância de superfície (Vermote et al., 2016).

Os arquivos vetoriais em formato shapefile referentes aos limites do município, área urbana e PNCG foram baixados via site do IBGE em https://downloads.ibge.gov.br/downloads_geociên cias.htm.

Os focos de queimadas que ocorreram na região foram obtidos do Banco de Dados de Queimadas, na página http://queimadas.dgi.inpe.br/queimadas/bdqueima das, para o período de 2013 a 2017.

Os dados meteorológicos diários e mensais de precipitação, temperatura e umidade relativa do ar utilizados foram adquiridos do Instituto Nacional de Meteorologia (INMET) em http://www.inmet.gov.br/portal/index.php?r=bdm ep/bdmep.

No intuito de estudar os eventos de queimadas em relação a cobertura vegetal foi utilizado o mapa temático no formato shapefile, produzido pelo Mapbiomas (2019) disponível no site https://mapbiomas.org e, em relação às declividades do terreno foi usado o MDE do Topodata (BRASIL, 2019) como produto de declividades na sua forma classificada.

Como ambiente computacional para o tratamento dos dados foram utilizados os softwares Erdas Imagine nos cálculos dos índices espectrais, o ArcGis 10.3 no recorte das imagens e na elaboração dos mapas e o excel 2016 na tabulação dos dados.

\section{Procedimentos Metodológicos}

Para efeito de simplificação e um melhor detalhamento a área de estudo foi dividida em áreas urbanas (I), remanescentes (II) e PNCG (III).

As 25 imagens foram importadas para o ambiente computacional do ArcGis 10.3 onde foi feita a reprojeção para o hemisfério Sul e 
posteriormente recortadas dentro dos limites do município com o auxílio da ferramenta Extract by Mask.

A partir dos valores de reflectâncias contidas nas bandas espectrais, B4 do visível (VIS), B5 do infravermelho próximo (NIR), B6 e B7 do infravermelho de ondas curtas (SWIR1 e SWIR2) do sensor OLI foram modelados dentro do ambiente computacional Erdas 2014, utilizando programação em phyton, 3 índices espectrais o NDVI (Normalized Difference Vegetation Index), NBR (Normalized Burn Ratio) e NBR2 (Variation of Normalized Burn Ratio) empregados por meio de métodos simples e dinâmico no mapeamento de áreas de vegetação afetadas pelo fogo (Pereira et al., 2016) e tem sido amplamente utilizados para detecção e mapeamento de áreas queimadas como nos trabalhos de (Fernandes et al., 2016; Pereira et al., 2016; Leite et al., 2017; Lotufo et al., 2020).

O NDVI desenvolvido por Rouse et al. (1974) normalizado linearmente entre os valores $1 \mathrm{a}+1$, representa áreas queimadas com valores mais próximos de -1 e apresenta baixa e alta reflectância, respectivamente, na banda do VIS e do NIR ao realçar queimadas (Libonatti et al., 2015), conforme a equação 1 .

$$
\mathrm{NDVI}=\frac{B_{4}-B_{5}}{B_{4}+B_{5}}
$$

Onde $\mathbf{B}_{4}$ e $\mathbf{B}_{5}$ são, respectivamente a reflectância do VIS e NIR.

O NBR relaciona-se áreas queimadas com as alterações das respostas espectrais, causando um decréscimo na reflectância no NIR e um acréscimo no SWIR1 devido à perda de água da planta e do solo caracterizadas pelos valores no range de -1 a +1 onde as áreas queimadas são representadas pelos valores mais próximos de -1.Tornou-se um índice espectral padrão para estudar áreas queimadas e o grau de intensidade do fogo (Melchiori et al, 2015; Pereira et al, 2016; Santos et al., 2017), conforme a equação 2 .

$$
\mathrm{NBR}=\frac{\mathrm{B}_{5}-\mathrm{B}_{7}}{\mathrm{~B}_{5}+\mathrm{B}_{7}}
$$

SWIR1.

Com $\mathrm{B}_{7}$ representando a reflectância do

O índice NBR2 destaca a sensibilidade da água na vegetação nas bandas do SWIR2 e auxilia na discriminação de áreas queimadas em imagens de satélites artificiais (Key e Benson, 2006). O índice NBR2 difere do NBR pela substituição da banda NIR usada no NBR pelo SWIR1 de acordo com a equação 3 .

$$
\mathrm{NBR} 2=\frac{\mathbf{B}_{\mathbf{6}}-\mathbf{B}_{\mathbf{7}}}{\mathbf{B}_{\mathbf{6}}+\mathbf{B}_{\mathbf{7}}}
$$

Sendo $\mathrm{B}_{6}$ a reflectância do SWIR1.

A validação dos focos de calor para o período seco de cada ano foi processada de forma visual nas imagens de referência por meio de composições coloridas RGB (Red, Green e Blue), resultantes dos valores médios dos índices NDVI, NBR e NBR2. Gerou-se polígonos, por meio de vetorização manual dos limites das áreas queimadas e os focos de calor acumulados foram quantificados pela sobreposição aos referidos polígonos.

O algoritmo estimador de densidade de Kernel contido na ferramenta Spatial Analyst Tools, Point Density do ArcGis 10.3 possibilitou estimar a intensidade de pontos na superfície estudada ao definir uma vizinhança circular nas proximidades de cada ponto amostrados, correspondente a um raio de influência (Oliveira, P. S; Oliveira. U. C, 2017), conforme a equação 4:

$$
\mathrm{f}(\mathrm{x})=\frac{1}{n h^{2}} \sum_{i=1}^{n} k\left\{\frac{x-X i}{h}\right\}
$$

Em que:

$\mathrm{K}=$ função de kernel;

$\mathrm{h}=$ raio de influência;

$\mathrm{x}=$ posição do centro dos pixels da imagem de saída;

$\mathrm{Xi}=$ posição de cada ponto proveniente do centróide de cada polígono;

$\mathrm{n}=$ número total de focos de calor.

Foram geradas e espacializadas áreas de densidade de fogo em 5 classes segundo a metodologia empregada por Brito e Ferreira (2015): Baixa, Moderada, Alta, Muito Alta e Extrema.

Neste sentido para atingir os objetivos deste estudo foi realizada uma análise das principais classes de vegetação que ocorrem na região, tais como formação florestal, formação savânica e pastagens onde ocorrem focos de calor no Cerrado com maior frequência, bem como o mapa de declividades reclassificado em 6 classes 
pela Embrapa (2018), 0-3\% (Plano); 3-8\% (Suave-Ondulado); $8-20 \%$ (Ondulado); $20-45 \%$ (Forte-Ondulado); 45-75\% (Montanhoso) e maior que $75 \%$ (Forte-Montanhoso). Por fim, foi calculado a porcentagem de áreas que ocorreram em cada uma dessas classes.

Para auxiliar nas análises da distribuição de queimadas, dados médios de precipitação, temperatura e umidade relativa do ar foram organizados no excel. Já os mapas temáticos de cobertura vegetal e topografia (declividades), foram sobrepostos com os mapas das classes de densidades de fogo geradas pela função de Kernel para avaliação das áreas queimadas e análise de sua dinâmica na área de estudo.

\section{Resultados e discussão}

\section{Variáveis micrometeorológicas}

A precipitação pluviométrica anual para o período estudado teve uma amplitude de 394,10 $\mathrm{mm}$, oscilando de 1282,40 mm em 2015 (ano mais seco) para 1676,50 $\mathrm{mm}$ em 2014 (ano mais chuvoso).

A quantidade de chuva acumulada nos meses secos é um dos fatores que determina a disponibilidade de água no solo e o estado da vegetação (Prado e Coelho, 2017) podendo impactar nas atividades de queimadas como mostra a Tabela 2.

Na estação seca, 2014 apresentou maior precipitação acumulada de $247,20 \mathrm{~mm}$ seguida de 2013 e 2017 que somaram 123,70 mm e 123,60 $\mathrm{mm}$, respectivamente. Já 2015 foi o ano que apresentou menor valor, $85 \mathrm{~mm}$, onde houve uma redução de 65,5\% em relação a 2014.

Menores temperaturas ocorreram nos meses de maio, junho, julho e agosto com a mínima de $24^{\circ} \mathrm{C}$ em 2016 e máxima de $28^{\circ} \mathrm{C}$ em 2017 , ocasião em que a Frente Polar vinda do extremo sul do país atua neste período (VAREJÃO, 2006). Setembro apresentou maiores temperaturas com mínima de $29^{\circ} \mathrm{C}$ em 2013 e máxima de $31^{\circ} \mathrm{C}$ em 2015.

Tabela 2: Variáveis micrometeorológicas utilizadas

\begin{tabular}{ccccc}
\hline ANO & $\begin{array}{c}\text { Precipitação } \\
\text { Total Anual (mm) }\end{array}$ & $\begin{array}{c}\text { Precipitação Total/ } \\
\text { Período seco (mm) }\end{array}$ & $\begin{array}{c}\text { Temperatura } \\
\text { Média do Ar/ } / \\
\left.\text { Período Seco ( }{ }^{\circ} \mathbf{C}\right)\end{array}$ & $\begin{array}{c}\text { Umidade Relativa } \\
\text { Média do Ar/ } \\
\text { Período seco (\%) }\end{array}$ \\
\hline $\mathbf{2 0 1 3}$ & 1524,40 & 123,70 & 26,47 & 63,64 \\
$\mathbf{2 0 1 4}$ & 1676,50 & 247,20 & 26,67 & 66,20 \\
$\mathbf{2 0 1 5}$ & 1282,40 & 85,20 & 27,37 & 62,69 \\
$\mathbf{2 0 1 6}$ & 1625,90 & 95,10 & 25,95 & 65,43 \\
$\mathbf{2 0 1 7}$ & 1623,30 & 123,60 & 27,65 & 59,97 \\
\hline
\end{tabular}

Fonte: Adaptado do INMET (2018).

Conforme Tabela 2 e considerando a temperatura média do ar no período seco estudado, foram constatadas temperaturas aproximadas, exceto o ano de 2016 que computou $25,95^{\circ} \mathrm{C}$.

A umidade relativa do ar teve média mínima de 59,97 (\%) em 2017, resultante das mínimas que houveram nos meses de setembro, além de poluentes do ar oriundo de fontes antropogênicas (móveis e estacionárias) e de queimadas de pastos, incêndios florestais e quintais (Blaskievicz, 2019) e média máxima de 66,20\% em 2014, o ano que ocorreu maior precipitação pluviométrica em todo o período.

\section{Focos de calor}

A Tabela 3 mostra a quantidade de focos de calor observados no município de Cuiabá na estação seca e a confirmação dentro dos polígonos de queimadas entre os anos de 2013 a 2017.

Do total de 5.485 focos de calor a maior quantidade (1.986) foram registrados em $2015 \mathrm{com}$ um percentual de $36,21 \%$, o que era esperado, uma vez que foi o ano que choveu menos, tornando-se o meio favorável a ocorrência de queimadas. Já em 2016 foi possível verificar uma menor quantidade de focos que o ano de 2017, apesar da pouca diferença de precipitação ocorrida para esses anos. 
Tabela 3: Focos de calor dos polígonos de referência no período seco.

Fonte: Adaptado de INPE (2019).

Considerando os focos de calor como ativos eles não coincidem na sua totalidade com as cicatrizes de queimadas ocorridas pois, existem condições que dificultam sua detecção como as frentes de fogo com menos de $30 \mathrm{~m}$, ocorrência dos incêndios, apenas no substrato das florestas densas, sem aflorar nas copas das árvores, além da imprecisão na localização do foco devido à baixa resolução espacial dos sensores dos satélites que os registraram (Francisco et al., 2020) como por exemplo, do total de focos registrados, apenas, $50,68 \%$ coincidiram com as áreas queimadas de referência realçadas pelos índices espectrais utilizados como mostra o recorte da imagem de 2015 na Figura 2.

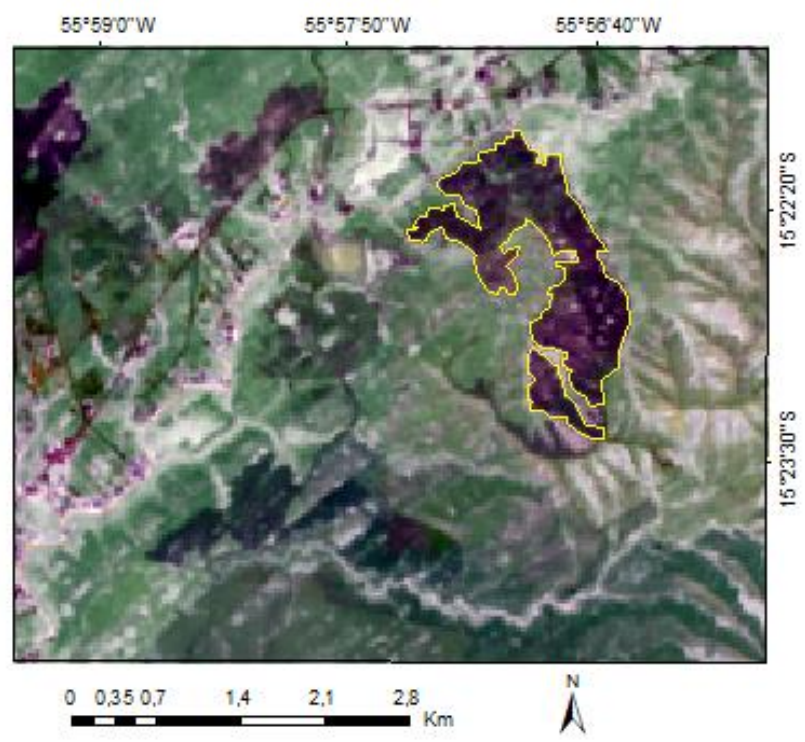

Figura 2: Recorte do trecho da imagem colorida de referência RGB de 2015. Fonte: Adaptado de INPE (2019).

Neste caso o INPE registrou o maior percentual de coincidência dos focos de calor dentro dos limites das cicatrizes da imagem de referência em 2017 de 72,12\% com um total de 1078 focos de calor para todo município na estação seca, bem como o maior número de cicatrizes detectadas. Já o ano mais seco do período estudado (2015) houve $49,04 \%$ de coincidência e o ano de maior ocorrência de precipitação pluviométrica, 2014, registrou o menor percentual, somando 12,95 $\%$.

\section{Distribuição espacial de queimadas}

Foram analisadas as influências da vegetação (Figura 3a) e declividades (Figura 3b),

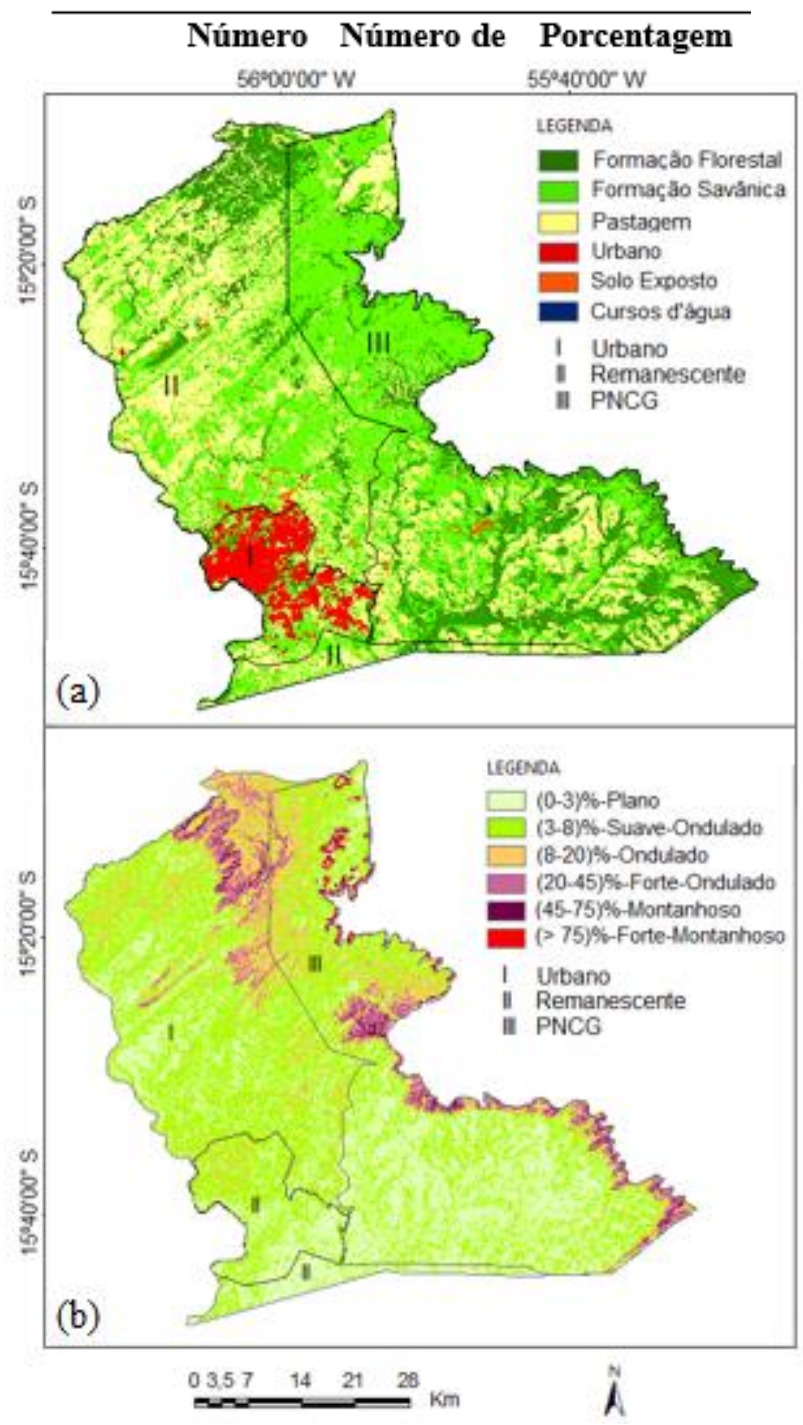

nas áreas I, II e III do município atingidas pelo fogo para cada ano e estação climática seca da série temporal de 2013 a 2017.

Figura 3: Mapa de uso do solo em (a) e de declividades em (b) do município de Cuiabá. Fonte: MAPBIOMA, INPE (2019).

A Tabela 4 mostra as áreas cobertas pelas classes de vegetação e declividades, destacando a classe formação savânica com maior percentual de área $(40,27 \%)$, o que corrobora com os resultados de Resende, Cardozo e Pereira (2017) para a região nordeste do Cerrado brasileiro, seguida pela classe pastagem com 32,78\% e a classe formação florestal com $18,23 \%$. Para as declividades, apresentaram maiores taxas as classes plano (0-3\%) com 44,42\% e suave-ondulado (3-8\%) com $37,27 \%$ em relação as demais (forte-ondulado a forte-montanhoso) que juntas somaram $7,99 \%$. 
Tabela 4. Valores das áreas das classes de vegetação e declividade do município de Cuiabá.

\begin{tabular}{lccllcc}
\hline \multicolumn{1}{c}{$\begin{array}{c}\text { Classes de } \\
\text { Vegetação }\end{array}$} & Áreas (ha) & $\begin{array}{c}\text { Áreas } \\
\text { (\%) }\end{array}$ & Classes de Declividades & Áreas (ha) & Áreas (\%) \\
\hline Formação Florestal & $58.773,04$ & 18,23 & $\mathbf{( 0 - 3 )}$ Plano & $143.240,62$ & 44,42 \\
\hline Formação Savânica & $129.870,80$ & 40,27 & $\mathbf{( 3 - 8 ) ~ S u a v e ~ O n d u l a d o ~}$ & $120.199,09$ & 37,27 \\
\hline Pastagem & $105.695,33$ & 32,78 & $\mathbf{( 8 - 2 0 )}$ Ondulado & $33.261,66$ & 10,31 \\
\hline Outros & $28.128,82$ & 8,72 & $\mathbf{( 2 0 - 4 5 )}$ Forte Ondulado & $17.676,88$ & 5,48 \\
\hline Total & 322.468 & 100,00 & $\mathbf{( 4 5 - 7 5 )}$ Montanhoso & $3.836,41$ & 1,19 \\
\hline & & & $\mathbf{( > 7 5 ) ~ F o r t e ~ M o n t a n h o s o ~}$ & $4.253,34$ & 1,32 \\
\cline { 4 - 6 } & & & Total & 322.468 & 100,00 \\
\cline { 4 - 6 } & & & &
\end{tabular}

Fonte: Própria dos Autores.

A Figuras 4 mostra a distribuição das estimativas dos eventos de queimadas em diferentes cores de graus de densidades (desde baixa (menos intensa) à extrema (mais intensa)). Foi considerado como alvo, nesta análise, os valores numéricos em hectares das áreas atingidas pelo fogo da classe extrema devido a condição mais desfavorável que apresenta para o meio ambiente.

No ano de 2013 verificou-se maiores concentrações na porção centro-norte e sudoeste do município e no entorno da área I. Na área III que abrange o PNCG, incluindo sua zona de amortecimento, 7.241,78 ha foram estimados, sendo $81,02 \%$ da área coberta pela classe de formação savânica e 9,56\% de pastagem, assim como o percentual de $51 \%$, representativa da classe de declividade suave-ondulado e de $17 \%$ da classe de declividade plano foram atingidas pelo fogo seguida de $30,46 \%$ da classe ondulado e com menor densidade no restante do parque. Nota-se, também, que a área concentrada no limite entre a área III e II infere que o fogo percorreu de fora para dentro do PNCG, provavelmente a partir de ações humanas.

A área II apresentou um acumulado de 27.714,03 ha concentrada próxima ao limite central da área III e da área I. Deste total, foram atingidas $54,42 \%$ da vegetação de formação savânica, $38,18 \%$ pastagem e $7,4 \%$ de formação florestal. Ainda, em declive suave-ondulado de 49,23\%, plano com $33,37 \%$ e ondulado de $14,26 \%$, respectivamente.

Em adição para a área I foi possível verificar uma maior concentração de queimadas fora de seu perímetro a norte e a leste. Em seu perímetro interno registrou-se uma área estimada de 932,04 ha computadas em $53,61 \%$ de formação savânica, 32,97\% de pastagem e 13,42\% de formação florestal, além da fração de $40,44 \%$ de terreno com declividade plano, 53,5\% suaveondulado, e $6,06 \%$ ondulado.

$\mathrm{O}$ ano de 2014, apresentou áreas queimadas bem distribuídas, exceto, na área III, porém, de menor tamanho em virtude da maior precipitação pluviométrica, concentrada mais a oeste do município.

$\mathrm{Na}$ área III, 4.435,18 ha foi obtida, sendo que $74,02 \%$, refere-se a classe de formação savânica, $19,36 \%$ de pastagem e 6,62\% de formação florestal. A classe de declividade mais atingida pelo fogo possui declive plano com $46,60 \%$, seguida pela classe suave-ondulado, $43,40 \%$ e ondulado, $10 \%$. Na área I pode-se notar a presença de sinais de queimadas mais intensas ao sul e sudeste. Obteve-se uma área estimada de $6.382,48$ ha, o que remete a um percentual de $47,10 \%$ da classe pastagem, $42 \%$ composta por formação savânica e 10,90\% de formação florestal, com maior influência do terreno de declive plano, $62,30 \%$ e suave-ondulado com $36,54 \%$. Para a área II, os polígonos avaliados somaram 14.068,97 ha. A classe de formação savânica foi atingida com $44,30 \%$, pastagem com $41,48 \%$ e formação florestal com $14,23 \%$. Já as classes de declividades suave-ondulado e plano registraram frequências mais altas de $47,80 \%$ e $37,20 \%$, respectivamente, e valores menores para as classes onduladas, $11,00 \%$ e forte-ondulado, $4,00 \%$.

Para o ano de 2015 foi registrado o menor índice pluviométrico, sendo o ano mais quente da série temporal analisada. Conforme a Figura 4, uma distribuição mais central das queimadas do 
município de densidades extrema e muito alta, preponderante, foi verificada, significando um ano que apresentou maior quantidade de áreas queimadas na área estudada. A porção a leste apresenta um contraste com o restante do município de baixa a moderada densidade.

Totalizou-se 22.132,84 ha de estimativa de áreas queimadas para o referido ano (2015) de densidade extrema na área III, a qual constatou-se
73,67\% da classe formação savânica, $15 \%$ de formação florestal e $11 \%$ de pastagem foram afetadas pelo fogo em terrenos com 44,50\% de declive suave-ondulado, $21,48 \%$ ondulado, $18,50 \%$ plano e $11,20 \%$ forte-ondulado.

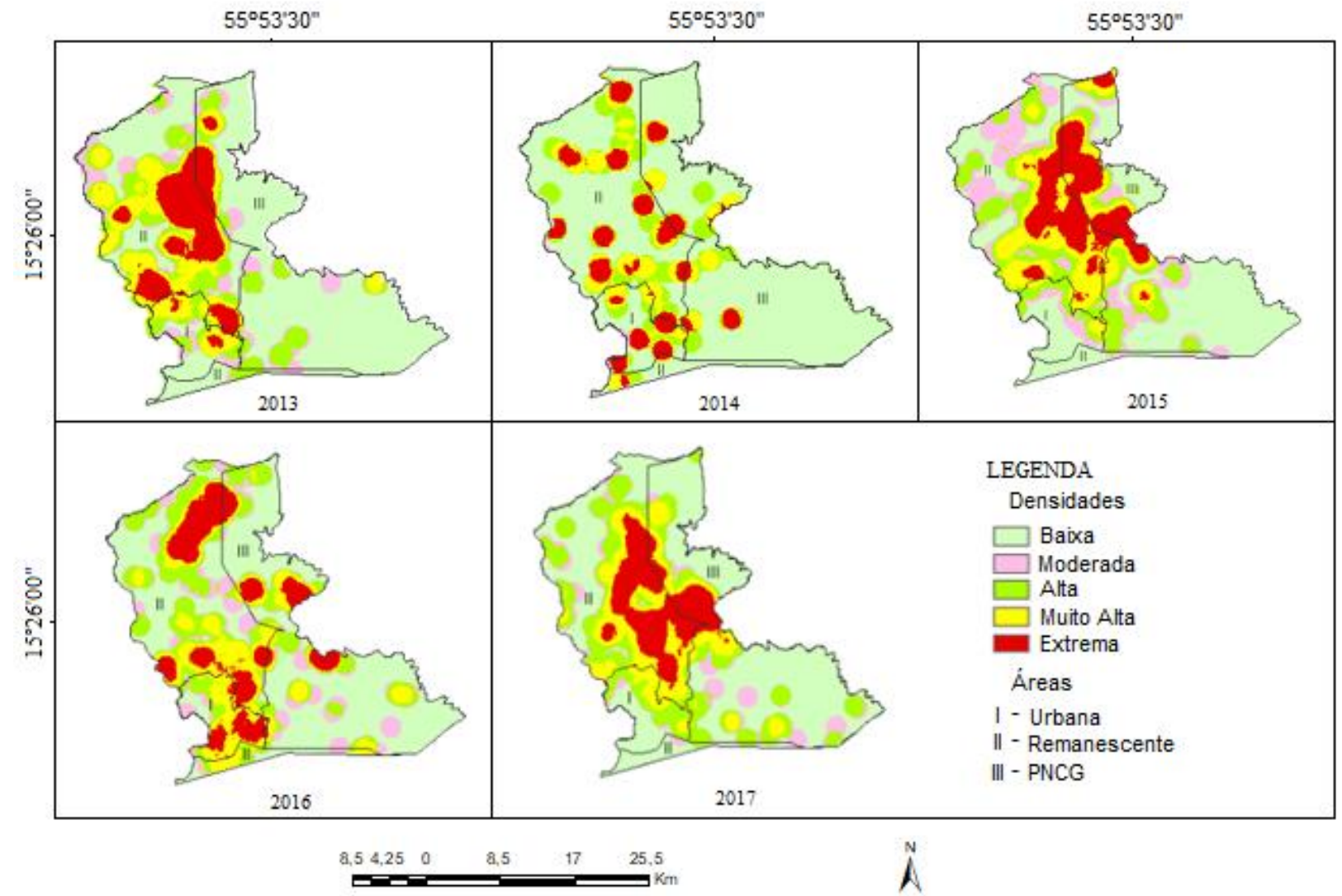

Figura 4. Mapas de densidades Kernel da estação seca do município de Cuiabá. Fonte: Própria dos Autores.

Analisando a área II, verificou-se uma área estimada de 25424,68 ha. A classe de vegetação formação savânica somou $57,75 \%$, a classe pastagem $35,55 \%$ e a formação florestal $6,70 \%$ de áreas atingidas. Desta área $48,66 \%$ de terreno suave-ondulado, $30,96 \%$ de terreno plano e $14,20 \%$ ondulado, foram afetadas. A área I não foi atingida pela classe de estimativa extrema e apresentou manchas pequenas situadas, externamente, no limite norte e leste, predominando as classes baixa e moderada.

Em 2016 as queimadas se concentraram com maiores densidades na porção sudoeste, dentro e no entorno da área I, a norte e a leste da área III a norte e centro-sul da área II.
A área I experimentou maior pressão do fogo de toda a série temporal com uma área estimada para a classe extrema de 6.627,40 ha. Destas, $48 \%$ foi atingida na classe pastagem, $46 \%$ formação savânica e $6 \%$ formação florestal,

apresentando $72,40 \%$ com declive plano e $27 \%$ suave-ondulado. Houve indícios de queimadas de densidades muito alta a extrema nas porções sudeste, sudoeste e nordeste onde se estendeu além do limite, devido à sua localização na interface com a área II onde apresenta diversos tipos de uso e cobertura do solo como edificações, lotes baldios, contendo gramíneas secas, solo exposto, pastagens, cultivos dentre outros. Estes tipos de cobertura do solo dentro e próximos a centros urbanos são considerados fatores importantes para iniciar um 
incêndio que na maioria das vezes são de origem criminal.

$\mathrm{Na}$ área III com 11.609,50 ha de área estimada, as queimadas mais frequentes e de densidades alta, muito alta e extrema ocorreram em sua porção central nas imediações do centro turístico da Salgadeira e na porção norte do parque, já as densidades baixa a muito alta na porção sudeste. As áreas afetadas pelas classes formação savânica acumulou um percentual de $65,40 \%$, de formação florestal $18,95 \%$ e pastagem $15,65 \%$ em toda extensão avaliada como classe de estimativa extrema pela função Kernel e atingiu, também, as classes de declividades suave-ondulado (34\%), ondulado $(26,20 \%)$, plana (22\%) e o declive mais acentuado, forte-ondulado com $14,60 \%$ situada nas partes elevadas do parque, divisa com o município de Chapada dos Guimarães. Na área II, 23.230,86 ha foram estimadas como classe de extrema densidade. As classes pastagem, formação savânica e formação florestal foram afetadas com $46,70 \%, 33,60 \%$ e $19,70 \%$, respectivamente. A classe suave-ondulada apresentou maior declive com $42,40 \%$, seguida de $28 \%$ da classe plano e $16,80 \%$ ondulado.

As queimadas mais frequentes com densidades entre alta, muito alta e extrema ocorreram na porção central da área II, incluindo a área III e extremo norte da área I com a área II na estação seca de 2017. Na estação seca o padrão da distribuição das queimadas referente às classes estimadas muito alta e extrema assemelha com o ano de 2015, apesar de maior precipitação pluviométrica ocorrido em 2017.

A área I apresentou queimadas de densidade entre moderada e muito alta nas porções norte e leste, respectivamente, com baixa densidade nas porções oeste e sul. Já na área III maiores densidades da classe estimada extrema e muito alta, encontra situado na região do balneário da Salgadeira e às margens da rodovia MT-251 que liga as cidades de Cuiabá e Chapada dos Guimarães. Foi computada uma área de 12.588,10 ha referente a classe estimada extrema onde a classe mais atingida foi a formação savânica com $66,42 \%$, seguida pela formação florestal com $19,30 \%$ e pastagem, $14,30 \%$. Os percentuais de áreas afetadas pelas classes de declividades mais acentuadas próximas as escarpas do Planalto dos Guimarães somam $22,70 \%$ de declive ondulado, $17,20 \%$ forte-ondulado, $17,20 \%$ montanhoso, $2,40 \%$ e o predomínio da classe suave-ondulado com $36,15 \%$.

$\mathrm{Na}$ área II do município um trecho longitudinal, contínuo, no sentido norte-sul, chegando até o limite com a área I da classe extrema, foi computada em $2.343,68$ ha e $57,68 \%$ da classe formação savânica, $34,70 \%$ da classe pastagem e $7,70 \%$ de formação florestal foram afetadas pelo fogo com maior intensidade. Já as classes de declividades atingidas foram as de declive suave-ondulado $(47,50 \%)$, plano $(31,80 \%)$, ondulado (16\%) e forte-ondulado $(4,50 \%)$.

\section{Conclusão}

$\mathrm{O}$ uso dos insumos derivados do sensoriamento remoto, mostrou-se eficiente para caracterizar e analisar as queimadas no município de Cuiabá.

A variação espaço-temporal das queimadas foram condizentes com as variáveis meteorológica uma vez que maiores quantidades de focos de calor e áreas queimadas ocorreram em anos de menor precipitação pluviométrica.

A vegetação e a declividade do terreno influenciaram na dinâmica espacial das queimadas. Ficou evidente que as tipologias vegetais mais afetadas pelo fogo foram as formações savânicas seguida da classe pastagem, passíveis ao processo de ignição e propagação do fogo. As classes de declividade mais atingidas foram as classes suaveondulado e plano que se coadunam com as formações de pastagem e cultivos agrícolas advindas de atividades antrópicas.

Foi possível estimar áreas com queimadas em locais de maior propensão pelo estimador pontual de Kernel. Possibilitando desta maneira, contribuir com trabalhos futuros envolvendo a dinâmica do Cerrado, auxiliar gestores locais a planejar ações de prevenção e combate ao fogo bem como conscientizar os habitantes no processo de redução das queimadas.

\section{Agradecimentos}

Os autores agradecem ao apoio da Universidade de Cuiabá - UNIC, Campus Barão pelo fornecimento da estrutura necessária ao desenvolvimento desse trabalho.

\section{Referências}

Blaskievicz, P. H. 2019. Lúpus eritematoso sistêmico: a influência da poluição atmosférica sobre a atividade da doença.Dissertação (Mestrado), Cuiabá. Universidade de Cuiabá.

Botelho, M. G. L, Furtado, L. G.; Lima, D. A.; Pimentel, B. S.; Machado, A. S. O.; Júnior, J. P.2020. A. Avaliação temporal e espacial de focos de calor em Paragominas, PA, Brasil, 9, p. 
2-16.

Brito, G. H. M; Ferreira, A. A. 2015. Identificação da Susceptibilidade a Ocorrência de Incêndios Florestais para o Estado de Goiás no ano de 2011. Revista Nucleus, 12p. 136-144.

CREA-MT-CONSELHO REGIONAL DE ENGENHARIA E AGRONOMIA DE MATO GROSSO. Entrevista: eu peço que deixem em paz nosso centro geodésico. 2009. Disponível em:https://www.crea-t.org.br. Acesso ago. 2019.

Daldegan, G.; Roberts, D.; de Figueiredo R.F. 2019. Spectral mixture analysis in Google Earth Engine to model and delineate fire scars over a large extent and a long time-series in a rainforest-savanna transition zone. Remote Sensing of Environment 232, 111340, 15 pp.

EMPRESA BRASILEIRA DE PESQUISA AGROPECUÁRIA. Sistema Brasileiro de Classificação de Solos. Brasília - DF. $5^{\text {a }}$ Edição.2018.

Ferreira, H. V. L.; Hugeda Júnior, J. C.2020. Variação da temperatura da superfície através de imagens aster em zonas climáticas locais da cidade de Cuiabá, Brasil. Revista Brasileira de Climatologia, 26, p. 393-410.

Fernandes, A. C. G.; Coutinho, M. A. N.; Santos, V. G.; Nascimento, C. R. 2016. Utilização de intervalos de índices de vegetação e temperatura da superfície para detecção de queimadas. Caderno de Ciências Agrárias, 8, p. 30-40.

Fiorelli, M. M.; Mazziero, F. F. F.; Vitti, D. M. C.; Junior, J. C. T. V. 2019. Mapeamento e disponibilização em ambiente web das ocorrências de queimadas urbanas: um estudo de caso no município de Jaú-SP. Revista de gestão e sustentabilidade ambiental, 8, p. 344-360.

INSTITUTO NACIONAL DE METEOROLOGIA. 2018. Estações Convencionais. Disponível: http://www.inmet.gov.br/portal/index.php?r=bd mep/bdmep. Acesso abr. 2018.

INSTITUTO CHICO MENDES DE CONSERVAÇÃO DA BIODIVERSIDADE. Manual para Formação de Brigadista de Prevenção e Combate aos Incêndios Florestais. 2020. Disponível em: https://www.icmbio.gov.br. Acesso mai 2020.

INSTITUTO NACIONAL DE PESQUISAS ESPACIAIS (INPE). BDqueimadas.Disponível em: http://www.inpe.br/queimadas/bdqueimadas. Acesso em nov. 2019.

INSTITUTO NACIONAL DE PESQUISAS ESPACIAIS (INPE). Topodata: banco de dados geomorfométricos do Brasil. Variáveis geomorfométricas locais. São José dos Campos, 2019.

Jesus, J. B.; Rosa, C. N.; Barreto, I. D. C.; Fernandes, M. M. 2020. Análise da incidência temporal, espacial e de tendência de fogo nos biomas e unidades de conservação do Brasil. Revista Ciência Florestal, 30, p. 176-191.

Junior, A. L. P.; Biudes, M.S.; Machado, N. G.; Arruda, A. G. R.; Santos, L. O. F.; Ivo, I. O.2020. Efeito da Mudança da Cobertura em Parâmetros Biofísicos em Cuiabá, Mato Grosso.Revista Brasileira de Geografia Física, 13, p. 1324-1334.

Key, C. H.; Benson, N. C. Landscape Assessment: sampling and analysis methods. USDA Forest Service Gen. Tech. Rep. Rocky Mountain Research Station General Technical Report RMRS-GTR-164-CD. 2006. p. 1-50.

Leite, C. C. S. S.; Santos, S. M. B. S.; Rocha, W. J. S. F.; Silva, A. B.; Batista, G. M. M.2017. Análise dos incêndios ocorridos no parque nacional da chapada diamantina-Bahia em 2008 e 2015 com suporte em índices espectrais de vegetação. Revista Brasileira de Cartografia, 69, p. 1127-1141.

Libonati, R.; Dacamara, C. C.; Setzer, A. W.; Morelli, F.; Melchiori, A. E. 2015. An Algorithm for Burned Area Detection in the Brazilian Cerrado Using MODIS Imagery. Remote Sens. 7, p. 15782-15803.

Lombardi, R. J. R. 2005. Estudo da recorrência de queimadas e permanências de cicatrizes do fogo em áreas selecionadas do cerrado brasileiro, utilizando, imagens tm/landsat. Dissertação (Mestrado). São José dos Campos.Instituto Nacional de Pesquisas Espaciais. Disponível em http://www.dpi.inpe.br/spring/portugues/arquiv os_publicacoes/Roberto_Lombardi.pdf.Acesso em set. de 2020.

Lopes, E. R, N.; Silva, A. P, P.; Peruchi, J. F.; Lourenço, R. W. 2018. Zoneamento de Risco de Incêndio e Queimadas no Município de Sorocaba - São Paulo. Revista do departamento de geografia, 36, p. 118-129.

Lotufo, J. B. S,; Machado, N. G.; Taques, L. M.; Mützenberg, D. M. S.; Neto, N. L.; Biudes, M. S.Índices Espectrais e Temperatura de Superfície em Áreas Queimadas no Parque Estadual do Araguaia em Mato Grosso.Revisa Brasileira de Geografia, 13, p. 648-663.

MAPBIOMAS. (2019). Coleção da Série Anual de Mapas de Cobertura e Uso de Solo do Brasil disponível no site https:// https://plataforma.mapbiomas.org/map\#coverag e. Acesso: out. 2019. 
Melchior, A. E.; Cândido, P. A.; Libonati, R.; Morelli, F.; Setzer, A. W.; Jesus, S. C.; Fonseca., L. M. G.; Körting, T. S. 2015. Spectral indices and multi-temporal change image detection algorithms for burned area extraction in the Brazilian Cerrado.In: XVII Simpósio Brasileiro de Sensoriamento Remoto - SBSR, 17. Anais. João Pessoa. Disponível: http://www.dsr.inpe.br/sbsr2015/acesso:jul.202 0.Oliveira, M. V. N.; White, B. L. A.; Ribeiro, G. T. 2018. Quantificação do material combustível em fragmento de Mata Atlântica no nordeste brasileiro. Brazilian Journal of Forestry Research, p. 2-8.

Oliveira, U. C.; Oliveira, P. S. 2017. Mapas de Kernel como Subsídio à Gestão Ambiental: Análise dos Focos de Calor na Bacia Hidrográfica do Rio Acaraú, Ceará, nos Anos 2010 a 2015. Revista Espaço Aberto, 7, p. 8799.

Pereira, A. A.; Teixeira, F. R.; Libonati, R.; Melchiori, E. A.; Carvalho, L. M. T. 2016. Avaliação de índices espectrais para identificação de áreas queimadas no cerrado utilizando dados landsat TM. Revista Brasileira de Cartografia 68, p. 1665-1680.

Prado, N. V.; Coelho, S. M. S. C.2017. Estudo da Variabilidade Temporal da Profundidade Óptica do Aerossol Utilizando Dados de Sensoriamento Remoto Sobre a Região de Transição entre a Floresta Amazônica e o Cerrado. Revista Brasileira de Meteorologia, 32, p. 649-658.

Resende, F. C.; Cardozo, F. S.; Pereira, G.2017. Análise Ambiental da Ocorrência das Queimadas na Porção Nordeste do Cerrado.Revista do Departamento de Geografia, 34, p. 31-42.

Ribeiro, T. M.; Mendonça, B. A. F.; OliveiraJunior, J. F.; Fernandes-Filho, E. I. 2020. Fire foci assessment in the Western Amazon (20002015).Environment, Development and Sustainability, p. 2-14.

Rodrigues, J. A.; Libonati, R.; Peres, L. F.; Seltzer, A. 2018. Mapeamento de Áreas Queimadas em Unidades de Conservação da Região Serrana do Rio de Janeiro Utilizando o Satélite Landsat-8 Durante a Seca de 2014. Anuário do Instituto de Geociências - UFRJ, 41, p. 318-327.

Sales, L. L. N.;Silva, D. D. S.; Lima, E. V.; Fonseca, G. T. C.; Almeida, G. S.; Rodrigues, J. B. 2019.10 municípios maranhenses mais atingidos por focos de queimadas NOAS ANODES de 2014 e 2015. Revista de Geografia, 36 , p. 60-74.

Santos, S. M. B.;Leite, C.C. S. S.; Rocha, W. J. S.
F.;Baptista, G, M. M.; Gonçalves, A. J. B. Análise do grau de severidade em área queimada no Parque Nacional da Chapada Diamantina, Bahia: estudo comparativo em dados dos sensores MUX-IRS\CBERS-4 e OLILANDSAT-8.In:XVII Simpósio Brasileiro de Sensoriamento Remoto - SBSR, 17. Anais. Santos-SP.Disponível:. Acesso: 25 jun. 2020.

Seger, C. D.2015.Material combustível e comportamento do fogo em vegetação de estepe gramíneo-lenhosa na RPPN caminho das tropas, Palmeira, Paraná. Tese (Doutorado). Curitiba. Universidade Federal do Paraná.USGS - United States Geological Survey. Landsat Mission. 2018.Disponível em https://landsat.usgs.gov. Acesso em abr. de 2020.

Silva F. S; Pestana, A. L. M; Martins, L. S.2019. Sensoriamento Remoto para Detecção de Queimadas no Cerrado Maranhense: uma aplicação no parque estadual do mirador. Rev. Geogr. Acadêmica ,13, p. 90-105.

Silva, C. V. J.;Costa, O. B.; Matricardi, E. A. T.2017.Detecção de cicatrizes do fogo na vegetação cerrado do distrito federal entre 1999 a 2011. Revista Brasileira de Cartografia, 4, p. 687-699.

USGS - United States Geological Survey. Landsat Mission. 2018.Disponível em https://landsat.usgs.gov. Acesso em abr. de 2020

Souza, I. M. P. 2017. Identificação de áreas queimadas por meio de índices espectrais em regiões do cerrado tocantinense. Dissertação (Mestrado). Gurupi, Universidade Federal do Tocantins. Disponível em https://repositório.uft.edu.br/handle/11612/696 Acesso em set. de 2020.

Varejâo-Silva, M.A. 2006. Meteorologia e Climatologia. Versão digital 2. Recife, Pernambuco. Brasil. 463p.

Vermote, E., Justice, C., Claverie, M., Franch, B., 2016. Preliminary analysis of the performance of the Lansat 8/OLI land surface reflectance product. Remote Sensing of Environment 185, 46-56.

White, B. L. A.; White, A. S. 2015. Queimadas controladas e incêndios florestais no estado de sergipe, brasil, entre 1999 e 2015. Revista Floresta 46, p. 561-570.

White, B. L. A.2018. Modelos matemáticos de previsão do teor de umidade dos materiais combustíveis florestais finos e mortos. Revista Ciência Florestal, 28, p. 432-445. 